\section{(2) OPEN ACCESS}

\title{
Severe statin-induced autoimmune myopathy successfully treated with intravenous immunoglobulin
}

\author{
Cansu Güngör, ${ }^{1}$ Udo Carl Wieshmann ${ }^{2}$
}

\begin{abstract}
${ }^{1}$ Medical Faculty Heidelberg, Heidelberg University, Heidelberg, BadenWürttemberg, Germany ${ }^{2}$ The Walton Centre for Neurology and Neurosurgery, Liverpool, UK
\end{abstract}

\section{Correspondence to} Dr Udo Carl Wieshmann; udo.wieshmann@ thewaltoncentre.nhs.uk

Accepted 30 April 2020

(C) BMJ Publishing Group Limited 2020. Re-use permitted under CC BY-NC. No commercial re-use. See rights and permissions. Published by BMJ.

To cite: Güngör $C$, Wieshmann UC. BMJ Case Rep 2020;13:e234805. doi:10.1136/bcr-2020234805

\begin{abstract}
SUMMARY
Statin-induced autoimmune necrotising myopathy causes a severe progressive muscle weakness even when the statins are discontinued. First-line treatment is usually with high dose steroids followed by immunosuppressants, but this is often ineffective and there is a high risk of side effects. We describe a diabetic patient who had a very severe statin-induced autoimmune myopathy. He made a full recovery with regular intravenous immunoglobulin (IVIg) infusion in relatively low dose (55g the first day followed by $50 \mathrm{~g} /$ day the second and third day, subsequently he was given $50 \mathrm{~g} /$ day for 3 days every 6 weeks). His symptoms relapsed when the IVIgs were discontinued for 28 weeks but remitted again following recommencement of IVIg infusions ( $50 \mathrm{~g} /$ day for 3 days every 7 weeks). Our case suggests IVIgs are an effective and well tolerated alternative to steroids and immunosuppressants.
\end{abstract}

\section{BACKGROUND}

Statins are among the most widely prescribed drugs. Myopathy is a rare but severe side effect of statins. Statin-induced necrotising autoimmune myopathy with anti 3-hydroxy-3-methylglutaryl-coenz yme A (HMG-CoA) antibodies is the most severe form of statin-induced myopathy. Unfortunately the weakness progresses even when the statins are discontinued. Treatment with steroids and immunosuppressants is often ineffective. We describe a patient with statin-induced autoimmune myopathy who was successfully treated with intravenous immunoglobulin (IVIg).

\section{CASE PRESENTATION}

A 65-year-old man was referred with proximal leg weakness. The weakness started about 2 months ago and got progressively worse. The patient had difficulties climbing stairs, getting up from the squatting position, walking or even putting on his trousers. He had started using a wheelchair outside the house. He denied having any associated pain, and upper limbs as well as speech and swallowing were uninvolved. He had longstanding mild sensory symptoms in both feet but no autonomic symptoms. $\mathrm{He}$ had also lost around $6 \mathrm{lb}$ (about $2.72 \mathrm{~kg}$ ) in weight in the previous month. He had been diagnosed with hypertension and type 2 diabetes mellitus 10 years ago and had taken atorvastatin $10 \mathrm{mg}$ and aspirin $75 \mathrm{mg}$ alongside antihypertensive (ramipril and amlodipine) and anti-diabetic (metformin, dapagliflozin, sitagliptin and gliclazide) medication since then.

On examination fasciculations and wasting were noticed in both quadriceps muscles. The muscular tone was normal. There was proximal weakness in both legs. Trendelenburg's and Gower's signs were positive. The knee jerks were brisk. Sensation was intact except loss of vibration sense up to the tibial plateau bilaterally which had been known to the patient for many years. Examination of the cranial nerves and the upper limbs was unremarkable.

\section{INVESTIGATIONS}

The creatine kinase (CK) level was raised up to $4292 \mathrm{U} / \mathrm{L}$ which was more than 10 times the normal range of $40-320 \mathrm{U} / \mathrm{L}$. The alanine transaminase (ALT) was raised to $234 \mathrm{U} / \mathrm{L}$ (normal range: 11-55 U/L). Alkaline phosphatase and bilirubin were normal. Autoantibodies against HMG-CoA reductase were positive. Haemoglobin A1C was $51 \mathrm{mmol} / \mathrm{mol}$. Full blood count, thyroid function tests, renal profile, vitamin $\mathrm{D}$ and $\mathrm{B}_{12}$ were all normal.

Electromyography (EMG) showed active denervation (fibrillation and positive sharp waves) and fasciculation potentials along with chronic denervation/re-innervation motor unit patterns (higher amplitude, increased duration and reduced interference patterns) from the craniobulbar, thoracic, paraspinal as well as upper and lower limb muscles.

\section{DIFFERENTIAL DIAGNOSIS}

The clinical findings with proximal weakness and preserved reflexes, and the raised ALT and CK were in keeping with an acquired myopathy. The EMG showed polyphasic short muscle action potentials in keeping with a myopathy. Spontaneous activity in the form of fasciculations (both clinically and on EMG) and positive sharp waves (on EMG) is seen in patients with inflammatory myopathies and must not be confused with motor neuron disease. ${ }^{1} \mathrm{~A}$ markedly raised CK like in our case is not compatible with motor neuron disease. ${ }^{2}$ The positive autoantibodies against HMG-CoA reductase confirmed the clinical diagnosis of 'statin-associated autoimmune myopathy. ${ }^{3} 4$

\section{TREATMENT}

Atorvastatin was stopped but the patient's muscle weakness deteriorated in his legs and also spread to his arms making immune-modulating treatment necessary. ${ }^{5}$ It is normally recommended to start the 
therapy with oral prednisolone $(1 \mathrm{mg} / \mathrm{kg}$ body weight) and to combine it with an immunosuppressive agent-like methotrexate, azathioprine or mycophenolate mofetil. ${ }^{5}$

However, due to potential side effects of glucocorticoids on the patient's diabetes mellitus, an alternative approach was considered in this case. Since a positive outcome with first-line therapy IVIg (gamunex 10\%) treatment was already reported for three diabetic patients, ${ }^{6}$ we decided for monotherapy with IVIg for the patient. A total dose of $155 \mathrm{~g}$ IVIg, equivalent to $1.6 \mathrm{~g} / \mathrm{kg}$ of body weight, was administered over 3 days. He received $55 \mathrm{~g}$ on the first day and $50 \mathrm{~g}$ on the second and third day. After the first administration, he developed a headache but he tolerated the second and third infusion and all subsequent infusions without side effects. He was 'feeling stronger' despite initial headaches and a lack of significant improvement of the CK. Nonetheless, since CK improvement was not expected before two or three treatment courses with IVIg, the treatment was continued every 6 weeks while slightly reducing the dose to $150 \mathrm{~g}$ because of the headache. After the third course of treatment, the CK in serum drastically fell to a mildly elevated level. Following the fourth administration, CK was stable around $500 \mathrm{U} / \mathrm{L}$ and weakness in his limbs had been greatly improved.

\section{OUTCOME AND FOLLOW-UP}

At the first follow-up, 7 weeks after the fourth round of IVIg, the patient nearly regained full strength in his legs and CK did not show any further increase. Taking potential severe adverse effects of IVIg into account, such as anaphylaxis, StevensJohnson syndrome, hypotension, myocardial infarction, cytopenia, haemolysis, pulmonary oedema, ${ }^{7}$ it was decided to stop IVIg infusions, and to solely monitor the symptoms and serum CK level instead.

However, 28 weeks later the patient's weakness returned and CK was elevated over $1500 \mathrm{U} / \mathrm{L}$. Treatment with IVIg was hereupon resumed at $50 \mathrm{~g}$ /day for 3 days every 7 weeks and resulted in a quick regression of the symptoms and CK which, already after the second course of IVIg, almost returned to the level before the flare-up. Following the next administration, the seventh in total, the patient reported almost full recovery of the muscle strength and his CK level was back in the normal range for the first time since the patient had been admitted to our clinic 1.5 years prior(figure 1 ).

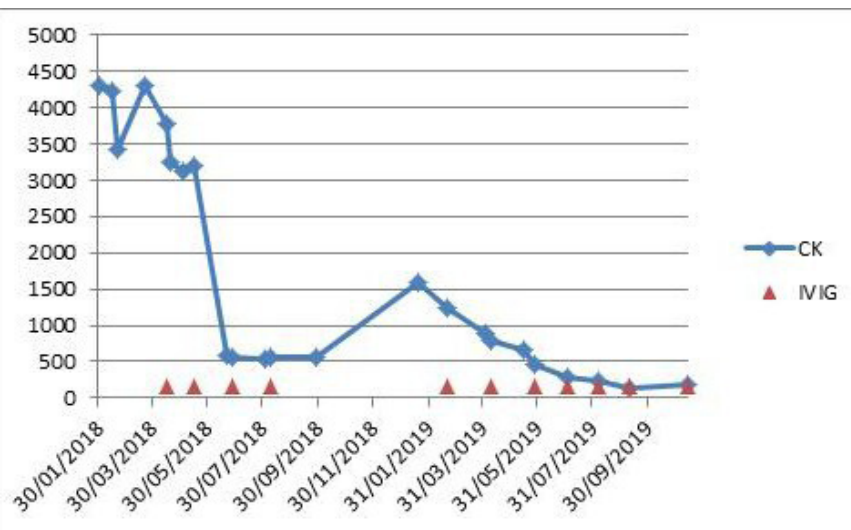

Figure 1 Creatine kinase level (U/L) in patient serum over time, from the admittance $(01 / 2018)$ to hospital until the latest round of IVIg infusion (11/2019). red arrowheads: rounds of IVIg infusions, spread over 3 days in each round (50 g/days). CK, creatine kinase; IVIg, intravenous immunoglobulin.

\section{DISCUSSION}

Muscle related adverse effects are common side effects of statins ranging from muscle pain and asymptomatic CK elevation to muscle weakness to rhabdomyolysis. ${ }^{8}$ Statin-induced myopathy affects 1.2 per 10000 patients and often manifests itself after 6 months of use. ${ }^{9}$ Although it is of non-immune and self-limiting character, in 2007 Needham et al described eight cases where the myopathy persisted or progressed following the cessation of statins, sarcolemmal major histocompatibility complex (MHC)-I expression was upregulated and strength in proximal muscles was recovered with an immunosuppressive therapy with prednisolone and methotrexate, indicating an immunological nature. ${ }^{10}$

Statin-induced autoimmune myopathy is a rare side effect of middle to long-term statin use which is seen in approximately 2-3 per 100000 patients treated with statins. ${ }^{5}$ The average age of onset is around 65 years of age $\mathrm{e}^{1112}$ and there is no sex predominance. ${ }^{11}$ It manifests itself as symmetrical proximal weakness which begins after several years of statin taking and may lead to immobility if untreated. The mean duration of statin use prior to symptom onset is approximately 41 months. ${ }^{11}$ Moreover, it is marked by significantly increased CK in blood, usually more than 10 times the upper limit of the normal range ${ }^{5}$ and autoantibodies against the enzyme HMG-CoA reductase. ${ }^{4}$ Our patient also presented with severely decreased strength of hip flexion, CK over $3000 \mathrm{U} / \mathrm{L}$ and was anti-HMG-CoA reductase antibodies positive.

Muscle oedema and necrosis can be detected on MRI ${ }^{12} 13$ while abnormal spontaneous activity in the form of fibrillation potentials, positive sharp waves and myotonic or pseudomyotonic discharges is commonly found on $\mathrm{EMG}^{14}$ along with small-amplitude motor-unit potentials. ${ }^{6}$ Long-duration, highamplitude motor unit patterns like in our patient are seen in (sub)acute and chronic stages of autoimmune myositis. ${ }^{15}$

Muscle biopsies, which are ordinarily considered to be part of the standard workup, demonstrate degeneration, necrosis and regeneration of myofibres ${ }^{414}$ and cellular infiltrates that are mainly constituted by macrophages and focused in endomysial and perivascular areas. ${ }^{16} \mathrm{CD} 4+$ and CD8 + lymphocytes as well as CD123 + plasmacytoid dendritic cells were also present in some samples. ${ }^{17}$ Besides, it is reported that MHC class I protein expression is up-regulated on the sarcolemma surface of nonnecrotic muscle fibres scattered diffusely throughout the endomysium. ${ }^{10} 16$ We did not proceed to a muscle biopsy, because of the distinctive combination of progressive bilateral proximal weakness with wasting, raised CK level and anti-HMG-CoA antibodies in blood.

Anti-HMG-CoA reductase-associated myositis constitutes a subtype of immune-mediated necrotising myopathies alongside antisignal recognition particle-associated myositis. The anti-HMG-CoA reductase antibodies are associated with prior statin use in two thirds of the cases, especially for those over 50, whereas anti-HMG-CoA reductase positive patients without statin exposure tend to be younger at the disease onset and have higher CK levels. ${ }^{4}$ A study found that anti-HMG-CoA reductase myopathy is more likely in the patients having type 2 diabetes mellitus or using atorvastatin (comparing with rosuvastatin and simvastatin). ${ }^{17}$ Both of these risk factors were also present in our case.

The exact pathogenesis of HMG-CoA autoimmunity is yet to be known. Nevertheless, class II HLA allele DRB1*11:01 is associated with a higher risk of developing anti-HMG-CoA reductase antibodies ${ }^{18}$ and may explain why some people are susceptible to this kind of autoimmune myopathy. Furthermore, the HMG-CoA 
reductase expression is increased in the presence of statins and in the regenerating muscle cells. ${ }^{5}$ These findings may suggest that overexpression of HMG-CoA reductase induced by statins triggers an autoimmune response in susceptible subjects. As muscles regenerate more due to the damage by autoantibodies, high levels of HMG-CoA reductase in regenerating muscles would maintain the autoimmune reaction in absence of statins as well. It would be interesting to know whether the levels of HMGCoA antibodies fell along with CK levels with IVIg treatment. Unfortunately, we are unable to report the anti-HMGCR titres because the method used was ELISA based and provided only qualitative data.

As statin-induced autoimmune myopathy very rarely improves spontaneously after stopping statins, ${ }^{11}$ an immunosuppressive treatment is needed except for in fairly mild cases. Notwithstanding, it is important to emphasise that no clinical trials have been conducted yet to determine the optimal treatment strategy. The most common therapy is prednisolone combined with at least another agent-like methotrexate, azathioprine or mycophenolate mofetil. ${ }^{5101419}$ In addition, these treatments can also be supported by adding IVIg or rituximab. ${ }^{13-15}$ Following adequate treatment, $90 \%$ of the patients see an improvement in muscle strength and decline in CK levels. ${ }^{11}$ Yet there have been cases described where the symptoms were resolved in spite of maintaining high CK or the enzymes returned to normal levels without alleviation of muscular problems. ${ }^{5}$

Mammen and Tiniakou report that three diabetic patients recovered full or partial strength with monthly IVIg $(2 \mathrm{~g} / \mathrm{kg}$ body weight) monotherapy even though CK elevations were persistent. ${ }^{6}$ This was also the strategy chosen in our case to preempt glucocorticoid side effects in our type 2 diabetic patient. However, we opted for a lower dose $(1.6-1.65 \mathrm{~g} / \mathrm{kg}) 150 \mathrm{~g} / 94 \mathrm{~kg}$ to minimise infusion reactions and in our case, not only muscle complaints were disappeared but also CK was normalised. Since IVIg can cause severe adverse effects like anaphylaxis, Stevens-Johnson syndrome, hypotension, myocardial infarction, thrombosis, haemolysis, stroke, seizure, loss of consciousness, acute respiratory distress syndrome, pulmonary oedema, acute bronchospasm and transfusion-associated lung injury ${ }^{7}$ it is very important to monitor the patient during and after the infusion. There is a potential and difficult to quantify risk of blood product related viral infection or transmission of Creutzfeldt Jakob disease.

Since the symptoms are reported to reappear following a statin rechallenge, ${ }^{10} 13$ life-long abstinence from statins is recommended. Alternative strategies like non-statin lipid lowering agents and lifestyle modification should be considered for longterm management of hyperlipidemia. Since our patient used statins merely for prophylactic reasons, we advised him to make dietary modifications and to reduce weight. It is also noteworthy that anti-HMG-CoA reductase positive patients should be carefully screened for cancer, since an increased risk of malignancy is observed in this condition after the age of 50 and within 3 years of the diagnosis. ${ }^{20}$

In conclusion, despite being relatively rare, statin-induced autoimmune myopathy can cause severe disability. Therefore, it must be taken into consideration if a patient presents with subacute progressive symmetrical proximal weakness and significantly raised CK, even if statins have been used for several years without obvious side effects. The prognosis is favourable if statins are discontinued and an adequate treatment is initiated as soon as the diagnosis is confirmed by anti-HMG-CoA reductase autoantibodies in blood. First-line treatment with IVIg offers a viable alternative to glucocorticoid-based therapies, especially for the patients, for whom an aggressive steroid regimen is contraindicated. However, efficacy of these treatment strategies must be tested and compared with other treatment options including rituximab in a clinical trial which has not been conducted so far.

\section{Learning points}

- Severe statin-induced autoimmune myopathy can occur after years of treatment with statins.

- Cessation of statins is not sufficient; immune-modulating treatment is required.

- Intravenous immunoglobulin is an alternative to steroids but long-term treatment is required.

Acknowledgements We would like to thank Carol Chadwick for proof reading the manuscript.

Contributors CG wrote the manuscript and performed the literature search. UCW suggested the case report, reviewed and revised the manuscript and is the treating doctor in this case.

Funding The authors have not declared a specific grant for this research from any funding agency in the public, commercial or not-for-profit sectors.

Competing interests None declared.

Patient consent for publication Obtained.

Provenance and peer review Not commissioned; externally peer reviewed.

Open access This is an open access article distributed in accordance with the Creative Commons Attribution Non Commercial (CC BY-NC 4.0) license, which permits others to distribute, remix, adapt, build upon this work non-commercially, and license their derivative works on different terms, provided the original work is properly cited and the use is non-commercial. See: http://creativecommons.org/ licenses/by-nc/4.0/.

\section{REFERENCES}

1 de Carvalho M, Dengler R, Eisen A, et al. Electrodiagnostic criteria for diagnosis of ALS. Clin Neurophysiol 2008;119:497-503.

2 Chahin N, Sorenson EJ. Serum creatine kinase levels in spinobulbar muscular atrophy and amyotrophic lateral sclerosis. Muscle Nerve 2009:40:126-9.

3 Christopher-Stine L, Casciola-Rosen LA, Hong G, et al. A novel autoantibody recognizing $200-k d$ and $100-k d$ proteins is associated with an immune-mediated necrotizing myopathy. Arthritis Rheum 2010;62:2757-66.

4 Mammen AL, Chung T, Christopher-Stine L, et al. Autoantibodies against 3-hydroxy-3methylglutaryl-coenzyme $A$ reductase in patients with statin-associated autoimmune myopathy. Arthritis Rheum 2011;63:713-21.

5 Mammen AL, myopathy S-associatedautoimmune. Statin-Associated autoimmune myopathy.. N Engl J Med 2016;374:664-9.

6 Mammen AL, Tiniakou E. Intravenous immune globulin for Statin-Triggered autoimmune myopathy. N Engl J Med 2015;373:1680-2.

7 Orange JS, Hossny EM, Weiler CR, et al. Use of intravenous immunoglobulin in human disease: a review of evidence by members of the primary immunodeficiency Committee of the American Academy of allergy, asthma and immunology. J Allergy Clin Immunol 2006;117:S525-53.

8 Bruckert E, Hayem G, Dejager S, et al. Mild to moderate muscular symptoms with high-dosage statin therapy in hyperlipidemic patients--the PRIMO study. Cardiovasc Drugs Ther 2005;19:403-14.

9 Sathasivam S, Lecky B, myopathy Sinduced. Statin induced myopathy.. BMJ 2008:337:a2286.

10 Needham M, Fabian V, Knezevic W, et al. Progressive myopathy with up-regulation of MHC-I associated with statin therapy. Neuromuscul Disord 2007;17:194-200.

11 Nazir S, Lohani S, Tachamo N, et al. Statin-Associated autoimmune myopathy: a systematic review of 100 cases. J Clin Rheumatol 2017:23:149-54.

12 Karunaratne K, Amiras D, Pickering MC, et al. Autoimmune necrotising myopathy and HMGCR antibodies. Pract Neurol 2018;18:151-5.

13 Babu S, Li Y. Statin induced necrotizing autoimmune myopathy. J Neuro/ Sci 2015:351:13-17

14 Grable-Esposito P, Katzberg HD, Greenberg SA, et al. Immune-Mediated necrotizing myopathy associated with statins. Muscle Nerve 2010;41:185-90.

15 Blijham PJ, Hengstman GJD, Hama-Amin AD, et al. Needle electromyographic findings in 98 patients with myositis. Eur Neurol 2006;55:183-8.

16 Chung T, Christopher-Stine L, Paik JJ, et al. The composition of cellular infiltrates in anti-HMG-CoA reductase-associated myopathy. Muscle Nerve 2015;52:189-95. 


\section{Novel treatment (new drug/intervention; established drug/procedure in new situation)}

17 Basharat P, Lahouti AH, Paik JJ, et al. Statin-Induced Anti-HMGCR-Associated myopathy. J Am Coll Cardiol 2016;68:234-5.

18 Mammen AL, Gaudet D, Brisson D, et al. Increased frequency of DRB 1 *11:01 in anti-hydroxymethylglutaryl-coenzyme a reductase-associated autoimmune myopathy. Arthritis Care Res 2012;64:1233-7.
19 Pinal-Fernandez I, Mammen AL. Spectrum of immune-mediated necrotizing myopathies and their treatments. Curr Opin Rheumatol 2016;28:619-24.

20 Allenbach Y, Keraen J, Bouvier A-M, et al. High risk of cancer in autoimmune necrotizing myopathies: usefulness of myositis specific antibody. Brain 2016;139:2131-5.

Copyright 2020 BMJ Publishing Group. All rights reserved. For permission to reuse any of this content visit

https://www.bmj.com/company/products-services/rights-and-licensing/permissions/

BMJ Case Report Fellows may re-use this article for personal use and teaching without any further permission.

Become a Fellow of BMJ Case Reports today and you can:

- Submit as many cases as you like

Enjoy fast sympathetic peer review and rapid publication of accepted articles

- Access all the published articles

Re-use any of the published material for personal use and teaching without further permission

Customer Service

If you have any further queries about your subscription, please contact our customer services team on +44 (0) 2071111105 or via email at support@bmj.com.

Visit casereports.bmj.com for more articles like this and to become a Fellow 